\title{
Efficacy and Safety of Amlodipine versus Captopril and their Combination in Hypertensive Urgency: A Randomized Controlled Trial
}

\section{Praew Kotruchin $^{1 *}$, Orathai Pachirat ${ }^{2}$ and Chatlert Pongchaiyakul ${ }^{2}$}

${ }^{1}$ Department of Emergency Medicine, Faculty of Medicine, Khon Kaen University, Khon Kaen, Thailand

${ }^{2}$ Department of Internal Medicine, Faculty of Medicine, Khon Kaen University, Khon Kaen, Thailand

"Corresponding author: Praew Kotruchin, Department of Emergency Medicine, Faculty of Medicine, Khon Kaen University, Khon Kaen, Thailand, Tel: 66-43-366869; Fax: 66-43-202401; E-mail: kpraew@kku.ac.th

Received: October 08, 2016; Accepted: November 14, 2016; Published: November 21, 2016

Copyright: $\odot 2016$ Kotruchin P, et al. This is an open-access article distributed under the terms of the Creative Commons Attribution License, which permits unrestricted use, distribution, and reproduction in any medium, provided the original author and source are credited.

\begin{abstract}
Objective: To compare the efficacy and safety of $10 \mathrm{mg}$ amlodipine, $12.5 \mathrm{mg}$ captopril and combination of $5 \mathrm{mg}$ amlodipine and $6.25 \mathrm{mg}$ captopril in patients with hypertensive urgency at emergency room.

Study design: This was a single-center, randomized, double-blinded clinical trial in hypertensive urgency patients (systolic blood pressure (SBP) $\geq 180 \mathrm{mmHg}$ and/or diastolic blood pressure (DBP) $\geq 110 \mathrm{mmHg}$ ). The patients were randomized to receive $10 \mathrm{mg}$ amlodipine (group A), $12.5 \mathrm{mg}$ captopril (group B) or combination of 5 $\mathrm{mg}$ amlodipine and $6.25 \mathrm{mg}$ captopril (group C). Blood pressure was measured every 30 minutes during 4 hours after administration. The therapeutic response was defined as $15 \%$ to $25 \%$ reduction in mean arterial blood pressure (MAP).
\end{abstract}

Results: Eighty-two patients were recruited (23, 28 and 31 patients in group A, B, and C, respectively). All three regimens achieved the blood pressure target around half of the patients $(52.2 \%, 53.5 \%$ and $51.6 \%$ in group $A$, $B$ and $\mathrm{C}$, respectively), but there was no statistical difference among three groups. There were only minor adverse events reported, i.e., headache, dizziness and fatigue, which were similar in all groups.

Conclusion: The efficacy of $10 \mathrm{mg}$ amlodipine, $12.5 \mathrm{mg}$ captopril and combination of 5 mg amlodipine with 6.25 mg captopril in treating patients with hypertensive urgency to achieve target blood pressure was comparable. No major adverse events were observed and minor adverse events were minimal among three groups. This finding suggested that three regimens could be safely used in emergency room for treating hypertensive urgency.

Keywords: Hypertensive urgency; Hypertensive crisis; Emergency room; Amlodipine; Captopril

\section{Background}

Hypertensive crisis patient defines as patient who has exceptionally high blood pressure (systolic blood pressure (SBP) $\geq 180 \mathrm{mmHg}$ and/or diastolic blood pressure (DBP) $\geq 110 \mathrm{mmHg}$ ) [1]. The 1993 report of the JNC proposed an operational classification of hypertensive crises as either "hypertensive emergency" or "hypertensive urgency" depending on end-organ involvement including cardiac, renal, and neurologic injury [2]. Distinguishing hypertensive emergency from urgency is critical in formulating a therapeutic plan. It has been accepted that patients with hypertensive emergency should have their blood pressure lowered within minutes to hours since it is a critical condition and rapid lowering of blood pressure is a cornerstone of treatment, whereas patients with hypertensive urgency should have their blood pressure reduced within $24 \mathrm{~h}$ to $48 \mathrm{~h}$ [3-6]. At present, standard practice guidelines for hypertensive emergency were developed and available for healthcare providers $[3,6]$. However, for hypertensive urgency, there is no standard practice guideline.

A variety of oral antihypertensive drugs are available to prescribe in patients with hypertensive urgency [5-8] and treatments are highly varied among hospitals and among doctors who work even at the same institute. Common drugs used for lowering blood pressure in hypertensive urgency are clonidine, nifedipine and captopril in Western countries [9-11], while a survey in our tertiary care setting (Srinagarind hospital) in 2013 found that hydralazine, amlodipine and angiotensin converting enzyme inhibitors (ACEIs) were commonly used for hypertensive urgency treatment in ER, the choice of which was based on physicians' preference.

It has been accepted that the effectiveness of blood pressure lowering in this condition means reducing mean arterial blood pressure (MAP) $15 \%$ to $20 \%$ from baseline within $4 \mathrm{~h}$ to $24 \mathrm{~h}[6,12,13]$. Since in hypertensive urgency, the severe increasing in BP does not lead to target organ damage, an immediate reduction in blood pressure is not necessary and initiation of oral anti-hypertensive therapy is generally appropriate. Moreover, the reduction of blood pressure in a short time span (as short as minutes to an hour) may be harmful since it can lead to myocardial infarction or cerebrovascular diseases $[14,15]$. With this in mind, anti-hypertensive drugs used in HT urgency are preferably administered in oral form such as calcium channel blockers (amlodipine, nifedipine), angiotensin converting enzyme inhibitors (captopril), hydralazine and beta-blocking agents (labetolol). However, there are no controlled studies which demonstrate long-term improved outcomes with acute treatment of hypertensive urgency and the drugs most effective in reducing blood pressure without causing side effects. 
Amlodipine is dihydropyridine calcium channel blocker. It lowers blood pressure by dilating vessels. An initial dose is $5 \mathrm{mg}$ per day subsequently increased to $10 \mathrm{mg}$ per day. Its side effects are usually subtle, i.e., pedal edema ( $2 \%$ to $15 \%)$, skin rash and pruritus ( $1 \%$ to $2 \%)$, nausea or abdominal pain ( $1 \%$ to $3 \%)$, flushing or palpitation ( $1 \%$ to $4 \%$ ), muscle cramp or weakness ( $1 \%$ to $3 \%$ ), and all side effects are dose related $[16,17]$.

Captopril is a drug that inhibits renin-angiotensin-aldosterone system (RAAS). The onset of action is rapid in minutes to hour. It is widely recommended to use in hypertensive crisis. The recommended initial dose is $6.25 \mathrm{mg}$ to $25 \mathrm{mg}$. Maximum dose is $100 \mathrm{mg}$ per day Side effects of captopril are skin rash ( $4 \%$ to $7 \%$ ), hyperkalemia ( $1 \%$ to $11 \%)$, coughing ( $1 \%$ to $2 \%$ ) and acute kidney injury particularly in dehydrated patients or patients with bilateral renal artery stenosis $[16,17]$.

In most situations, only one antihypertensive drug (monotherapy) does not provide adequate therapeutic response. Second drug combination is often administered to achieve a balanced and additive antihypertensive effect with minimum adverse effects [18-20]. An understanding of differences in the mechanism of action of these agents allows a logical approach for the use of these agents as a combination therapy [16]. Even though, previously reports demonstrate that the combination of these drugs is effective in hypertensive patients, there is no previous study to determine the efficacy of the combination compared with single agents and also a lack of data to evaluate the efficacy and adverse events when using halfdose of amlodipine-captopril in combination for hypertensive urgency patients.

The present study's primary objective is to compare the efficacy of three regimens of antihypertensive agents $(10 \mathrm{mg}$ amlodipine, $12.5 \mathrm{mg}$ captopril and combination of $5 \mathrm{mg}$ amlodipine and $6.25 \mathrm{mg}$ captopril) in reducing MAP of $15 \%$ to $25 \%$ from the baseline in hypertensive urgency patients. The secondary objective was to examine the adverse events of these three regimens during treatment at emergency room.

\section{Materials and Methods}

\section{Study design and setting}

This study was a single-center, randomized, double-blinded clinical trial. We conducted the study in hypertensive urgency patients who presented at emergency outpatient department, Srinagarind hospital during August 2013 to December 2014. The study was formally approved by the Khon Kaen University Ethics Committee for Human Research. The written informed consent was obtained from each individual and the study protocol conformed with the ethical guidelines of the 1975 Declaration of Helsinki.

\section{Inclusion and exclusion criteria}

The inclusion criteria were patients from both genders who age between 35 years to 65 years old with a diagnosis of hypertensive urgency with thresholds determined by the Joint National Committee on Prevention, Detection, and Evaluation and Treatment of High Blood Pressure defined as a systolic blood pressure (SBP) $\geq 180 \mathrm{mmHg}$ and/or a diastolic blood pressure (DBP) $\geq 110 \mathrm{mmHg}$ after two measurements, ten minutes apart in the supine position. Patients were excluded if they exhibited any of the following criteria: a decrease in blood pressure after bed rest (15\% to $20 \%$ from baseline), known chronic kidney disease or baseline serum creatinine $>1.5 \mathrm{mg} / \mathrm{dl}$ within one month, known secondary hypertension (i.e., endocrine hypertension, arteritis, and drug induced hypertension), women who were pregnant or breast feeding, myocardial infarction with symptoms such as chest pain and abrupt variations in their electrocardiograms, pulmonary edema, cerebral symptoms of hypertensive encephalopathy and stroke, aortic dissection, ocular conditions, allergy to amlodipine or captopril and received an antihypertensive drug within the prior $60 \mathrm{~min}$.

\section{Randomization}

Randomization was conducted using a permuted block design with random block sizes of 3,6 , and 9 using STATA (version 18.0). Randomization sequences were manually generated by the investigator who was not involved in treating the patients; placed in consecutively numbered, sealed, opaque envelopes; and opened only after obtaining each patient's consent to participate in the study.

\section{Intervention}

After patients were enrolled, they were taken to a restricted area of emergency room for $10 \mathrm{~min}$ of rest then blood pressure was measured in lying position with an automatic sphygmomanometer by a trained nurse and the higher blood pressure was used for analysis. Doctors examined subjects thoroughly to detect target organ damage. Blood samples were collected for complete blood count, the kidney function test and electrolytes measurement in all cases. Urine pregnancy test and urine toxic screening including cocaine and amphetamine were done in suspected cases.

After measuring a blood pressure, the patients were randomized to receive treatment regimens including $10 \mathrm{mg}$ amlodipine (group A), $12.5 \mathrm{mg}$ captopril (group B) or combination of $5 \mathrm{mg}$ amlodipine and $6.25 \mathrm{mg}$ captopril (group C) (Figure 1). The drug names were blinded to all patients, heath care workers and study team. The patients' blood pressure measurement was taken every $30 \mathrm{~min}$, totally 8 times (at 30 min, $60 \mathrm{~min}, 90 \mathrm{~min}, 120 \mathrm{~min}, 150 \mathrm{~min}, 180 \mathrm{~min}, 210 \mathrm{~min}$ and 240 min) after treatment administration. Both SBP and DBP were measured and any reported side effects and complications were recorded until the primary endpoint was reached or the termination criteria were observed.

\section{Statistical analysis}

Data were analyzed according to the randomly assigned groups of the participants, and all analyses were made on an intention-to-treat basis. Descriptive indices such as frequency, mean and standard deviation (SD) were used. Baseline characteristics of the enrolled subjects were presented to check balance among group A, B and C using the unpaired t-test or Fisher's exact test. The success of treatment (\% of MAP controlled to the goal) between the three groups were compared using Chi-square test. The 95\% confidence interval was reported and differences were statistically significant at level of $5 \%$ $(\mathrm{P}<0.05)$. All statistical analyses were performed using the STATA statistical package (version 18).

\section{Results}

Ninety-six patients with hypertensive urgency were identified for study inclusion (Figure 2). From those, 14 patients were excluded due to previous chronic kidney disease $(n=3)$, age more than 65 years $(n=1)$, incomplete data $(n=6)$, and decreasing of blood pressure after 
Citation: Kotruchin P, Pachirat O, Pongchaiyakul C (2016) Efficacy and Safety of Amlodipine versus Captopril and their Combination in Hypertensive Urgency: A Randomized Controlled Trial. J Gen Pract (Los Angel) 4: 274. doi:10.4172/2329-9126.1000274

Page 3 of 7

bed rest $(n=4)$. After exclusions, 82 patients ( 28 men and 54 women) were enrolled for analysis. Participants were randomized into three groups. There were 23,28 and 31 patients randomized to receive $10 \mathrm{mg}$ amlodipine (group A), $12.5 \mathrm{mg}$ captopril (group B) and combination of $5 \mathrm{mg}$ amlodipine and $6.25 \mathrm{mg}$ captopril (group C), respectively.

The average age was 49.5 years old, 52 years old and 53.2 years old in group A, B and C, respectively and less than half of the patients had family history of hypertension in first degree relatives. There were no significant differences in age, duration of hypertension, clinical symptoms related with hypertension, prior hypertension treatment, discontinue antihypertensive drugs, family history of hypertension, herbal use among three groups; however, numbers of patients who had prior emergency room visiting due to hypertensive crisis trended to be higher in group C (41.9\%) compared with $17.4 \%$ and $14.8 \%$ in group A and $\mathrm{B}$, respectively. Interestingly, although there was no significant difference in salt intake and exercise among three groups, but most of patients $(60 \%)$ who visited emergency room already restricted salt intake and only few patients had regular exercise. Moreover, there were no significant differences in serum creatinine, electrolytes, and left ventricular hypertrophy by electrocardiography and chest radiography among the groups, however, left ventricular hypertrophy detected by both techniques was higher in group B (45.5\%) than group A $(21.2 \%)$ and group C (33.3\%) (Table1).

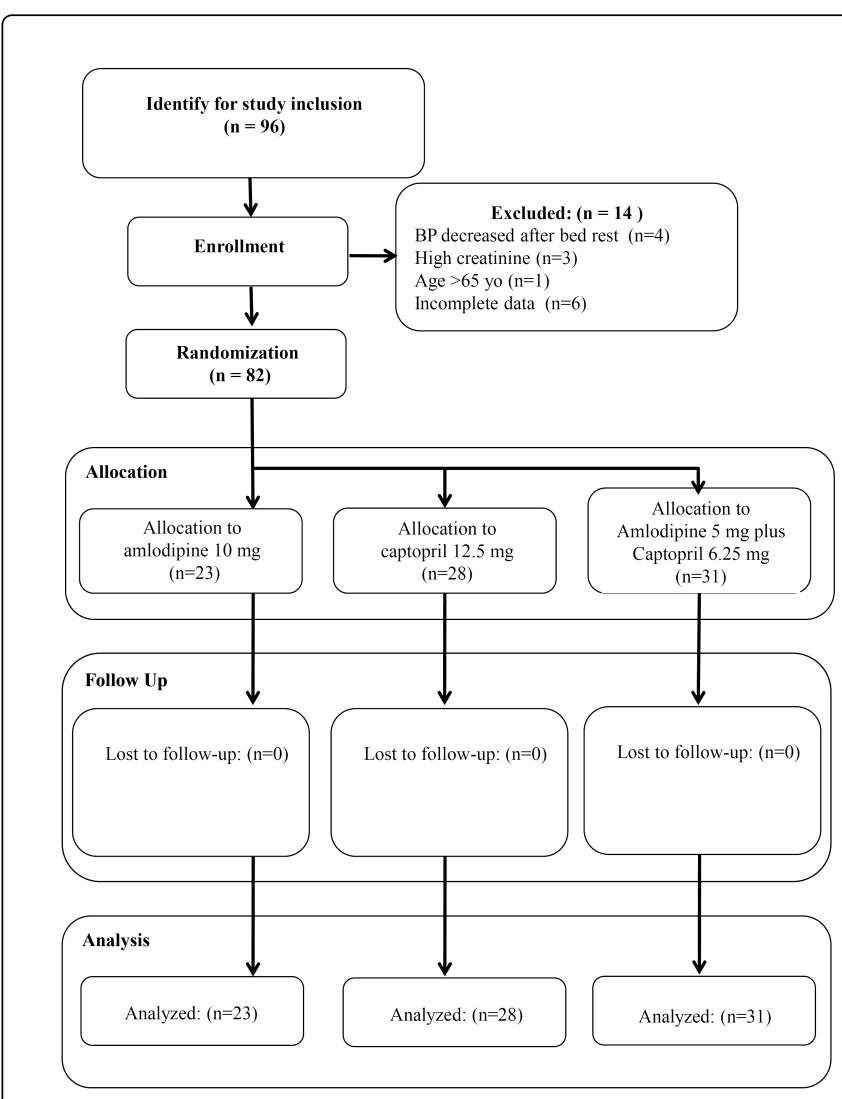

Figure 1: Study design.

In this study, most patients visited emergency department due to accidentally finding of significantly high blood pressure from other clinics. Among all, 26 patients $(31.7 \%)$ had clinical symptoms related with high blood pressure, i.e., dizziness, headache and fatigue, etc.
Forty-eight patients (58.5\%) were diagnosed hypertension and were already taken antihypertensive drugs $(56.5 \%, 59.3 \%$ and $61.3 \%$ in group A, B and C, respectively).

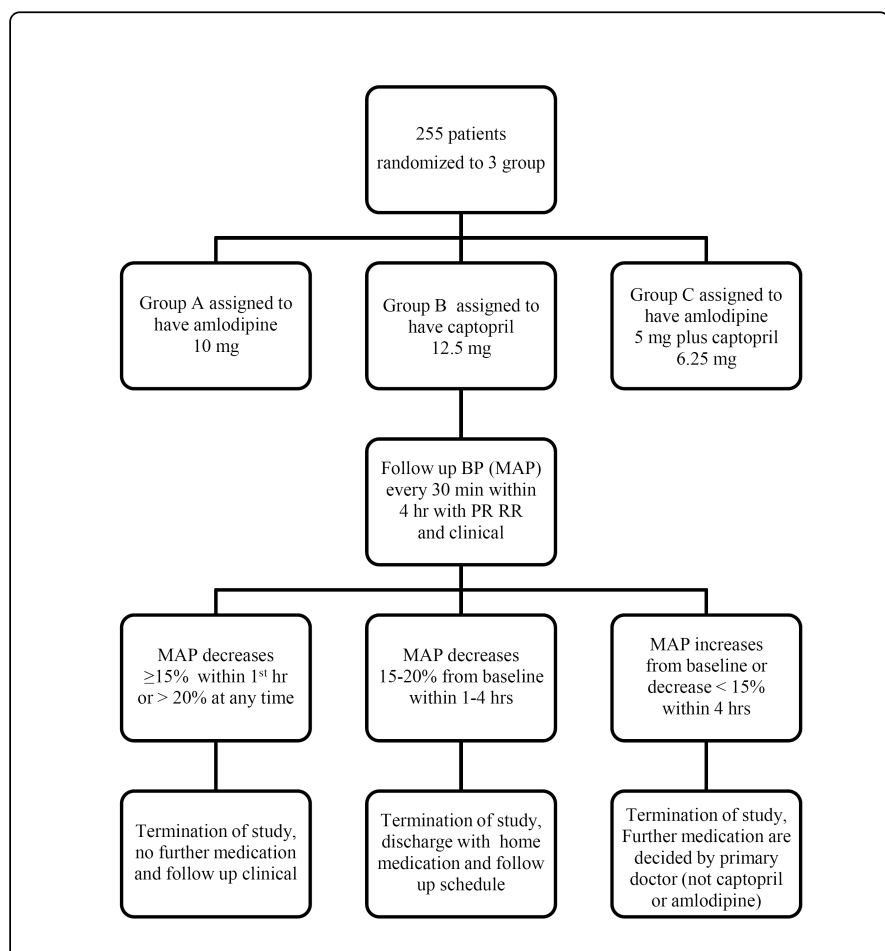

Figure 2: Flow diagram of patient recruitment and randomization.

The primary endpoint in this study was to reduce mean arterial blood pressure (MAP) $15 \%$ to $25 \%$ from baseline. If MAP was higher than baseline, decrease less than $15 \%$ or decrease more than $25 \%$ from baseline or decrease too fast (more than $15 \%$ within $1^{\text {st }}$ hour) would be considered out of goal. Based on preliminary results of 82 patients, the numbers of patients who achieve goal were comparable among three groups $(52.2 \%, 53.5 \%$ and $51.6 \%$ in group $\mathrm{A}, \mathrm{B}$ and $\mathrm{C}$, respectively); and $32.6 \%$ and $67.5 \%$ reached the target within $1 \mathrm{~h}$ and $2 \mathrm{~h}$, respectively. We found that the percentage of achieving target within first hour was highest in group A (41.7\%), while within two hours, the percentage was highest in group B (80\%) compared with $58.4 \%$ and $62.5 \%$ in group A and C, respectively. Despite all patients received antihypertensive drugs, 12 of 82 patients (14.6\%) still increased in blood pressure after treatment which found $21.7 \%, 14.3 \%$ and $9.7 \%$ in group A, B and C, respectively (Table 2).

The changes in MAP, SBP and DBP among three groups were shown in Figures 3-5. We found that the MAP, SBP and DBP in group B (12.5 $\mathrm{mg}$ captopril) and group $\mathrm{C}(5 \mathrm{mg}$ amlopine $+6.25 \mathrm{mg}$ captopril) decreased faster than group A, particularly within the first 120 min and then increasing after $120 \mathrm{~min}$ and $150 \mathrm{~min}$ in group B and C, respectively. All MAP, SBP and DBP of patients in group A $(10 \mathrm{mg}$ amlodipine) decreased overtime up to $210 \mathrm{~min}$ and then trending toward higher level. In this study, blood pressure reduced beyond $15 \%$ within $4 \mathrm{~h}$ in 57 subjects (responders), while 25 subjects were nonresponders. The responders had significantly higher in MAP at baseline compared with non-responders $(145.4 \mathrm{mmHg} \pm 14.1 \mathrm{mmHg}$ and $136.4 \mathrm{mmHg} \pm 9.9 \mathrm{mmHg}$ in responder and non-responder group, respectively) with mean difference of $8.97 \mathrm{mmHg}$ (95\% CI 3.5-14.4, 
Citation: Kotruchin P, Pachirat O, Pongchaiyakul C (2016) Efficacy and Safety of Amlodipine versus Captopril and their Combination in Hypertensive Urgency: A Randomized Controlled Trial. J Gen Pract (Los Angel) 4: 274. doi:10.4172/2329-9126.1000274

Page 4 of 7

$\mathrm{p}<0.01)$. However, other factors, i.e., age, serum creatinine and duration of hypertension were not significantly difference between responder and non-responder groups (Table 3).

In term of safety and adverse events, the proportion of overall patients who decreased in MAP more than the safety criteria (reduction $>25 \%$ of the baseline at any times or $>15 \%$ in the first hour) was $17.1 \%$ (14 of 82$)$, which was highest in group C (25.8\%, 8 of 31$)$ compared with group A (4.4\%, 1 of 23$)$ and group B (17.9\%, 5 of 28), however there were no statistical significantly differences among groups (group A vs. group $\mathrm{B}, \mathrm{p}=0.204$; group $\mathrm{A}$ vs. group $\mathrm{C}, \mathrm{p}=0.06$; group B vs. group $\mathrm{C}, \mathrm{p}=0.540$ ).

In this study, there were only minor adverse events reported, i.e., headache, dizziness and fatigue. Mild degree of headache was the most common adverse event, which found in 9 patients $(2,5$ and 2 patients in group A, B and C. respectively). There was one patient in group A who had experienced dizziness, another 2 patients in group A felt fatigue and one patient in group $\mathrm{C}$ had backache after treatment but only mild symptom.

\begin{tabular}{|c|c|c|c|}
\hline Characteristics & Amlodipine (10 mg) & Captopril (12.5 mg) & Amlodipine $(5 \mathrm{mg})+$ Captopril $(6.25 \mathrm{mg})$ \\
\hline Number of patients & 23 & 28 & 31 \\
\hline \multicolumn{4}{|l|}{ Sex } \\
\hline Men & $10(43.5)$ & $10(35.7)$ & $8(25.8)$ \\
\hline Women & $13(56.5)$ & $18(64.3)$ & $23(74.2)$ \\
\hline Age (year) & $49.52(9.6)$ & $52(8.7)$ & $53.2(9.5)$ \\
\hline $\begin{array}{l}\text { Chief complaint associated } \\
\text { with } \mathrm{HT}\end{array}$ & $10(43.5)$ & $6(21.4)$ & $10(32.3)$ \\
\hline Duration of HT (month) & $27.6(39.6)$ & $31.7(37.6)$ & $33.6(44.7)$ \\
\hline Prior HT treatment & $13(56.5)$ & $16(59.3)$ & $19(61.3)$ \\
\hline Prior ER visit due to $\mathrm{HT}$ urgency & $4(17.4)$ & $4(14.8)$ & $13(41.9)$ \\
\hline Discontinuation of antihypertensive drug & $7(30.4)$ & $8(29.6)$ & $11(35.5)$ \\
\hline Herbal use & $2(8.7)$ & $5(18.5)$ & $5(16.1)$ \\
\hline Salt restriction & $14(60.9)$ & $18(66.7)$ & $20(64.5)$ \\
\hline Regular exercise & $5(21.7)$ & $2(7.4)$ & $4(12.9)$ \\
\hline Family history of hypertension & $10(43.5)$ & $11(40.7)$ & $11(35.5)$ \\
\hline Creatinine & $0.8(0.2)$ & $0.8(0.2)$ & $0.8(0.3)$ \\
\hline Sodium & $137.5(3.7)$ & $139.2(3.1)$ & $138(3.6)$ \\
\hline Potassium & $3.9(0.4)$ & $3.9(0.3)$ & $3.9(0.5)$ \\
\hline Bicarbonate & $25.2(3.5)$ & $24.8(2.3)$ & $24.4(2.8)$ \\
\hline Chloride & $99.6(3.9)$ & $101.3(3.4)$ & $99.9(3.2)$ \\
\hline Left ventricular hypertrophy & $7(35.0)$ & $15(62.5)$ & $11(39.3)$ \\
\hline
\end{tabular}

Table 1: Baseline characteristics of the study subjects.

\section{Discussion}

Hypertensive urgency is common clinical occurrence that may account one fourth of all emergencies presenting to the emergency department. Although most patients have only mild symptoms such as headache, dizziness, tiredness and chest tightness without or delay lowering blood pressure may further to target organ damage. Notwithstanding, clinical practice management of this condition varies considerably [21]. The variability is because of the lack of evidence supporting the use of one therapeutic agent over another and at present, there is no specific practice guideline for treatment patients with hypertensive urgency.
This present study was designed to determine the efficacy in term of the agents' ability to reach a target blood pressure and to examine safety of commonly used medications including amlodipine, captopril. However, to reduce complication of both drugs, we also investigated the half-dose combination of amlodipine and captopril.

We found that all three regimens achieved the blood pressure target within $4 \mathrm{~h}$ around half of patients (51.6\% to $53.5 \%$ ), with the highest percentage in $12.5 \mathrm{mg}$ captopril group, but there was no statistical significance among three groups. In patients who did not achieve the targets (increased MAP or less than 15\% decreased in MAP after drugs administration), the failure rate was highest in patients in $10 \mathrm{mg}$ amlodipine group $(43.4 \%, 10 / 33)$, while lower failure rate was in 12.5 
Citation: Kotruchin P, Pachirat O, Pongchaiyakul C (2016) Efficacy and Safety of Amlodipine versus Captopril and their Combination in Hypertensive Urgency: A Randomized Controlled Trial. J Gen Pract (Los Angel) 4: 274. doi:10.4172/2329-9126.1000274

Page 5 of 7

$\mathrm{mg}$ captopril and $5 \mathrm{mg}$ amlodipine plus $6.25 \mathrm{mg}$ captopril group. The findings from this study were difficult to compare with previous studies, since many studies defined hypertensive urgency differently, had small sample size and differences in methodology, study designs, contamination, therapeutic response, lack of long-term blood pressure control ( $>24 \mathrm{~h}$ after administration) and also different cardiovascular endpoints.

\begin{tabular}{|l|l|l|l|}
\hline Mean blood pressure outcomes & Amlodipine $\mathbf{1 0} \mathbf{~} \mathbf{g}(\mathbf{n}=\mathbf{2 3}) ; \mathbf{n}(\%)$ & Captopril 12.5 $\mathbf{~ m g ~ ( n = 2 8 ) ; ~} \mathbf{n}(\%)$ & Amlodipine $\mathbf{5}$ mg + Captopril 6.25 $\mathbf{~ m g ~ ( n = 3 1 ) ; ~} \mathbf{n}(\%)$ \\
\hline Increase & $5(21.7)$ & $4(14.3)$ & $3(9.7)$ \\
\hline Decrease $<15 \%$ & & & \\
\hline Decrease $15 \%$ to $25 \%$ & $5(21.7)$ & $4(14.3)$ & $4(12.9)$ \\
\hline Decrease $>15 \%$ at first hour or & $12(52.2)$ & $15(53.5)$ & $16(51.6)$ \\
\hline$>25 \%$ at any times & $1(4.4)$ & $5(17.9)$ & $8(25.8)$ \\
\hline
\end{tabular}

Table 2: Primary endpoints.

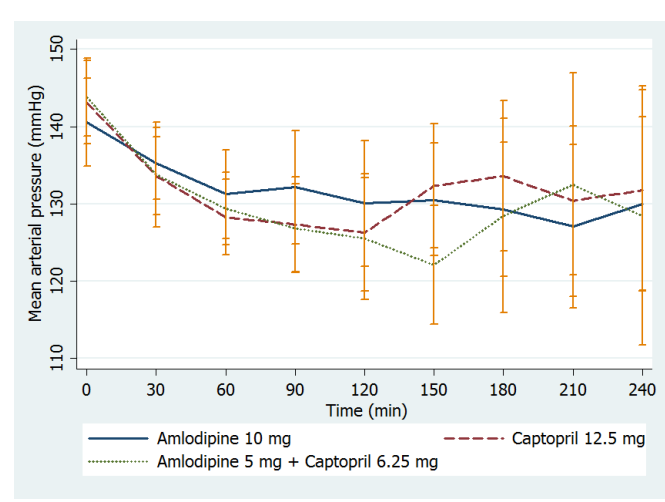

Figure 3: Mean arterial pressure trend during study period.

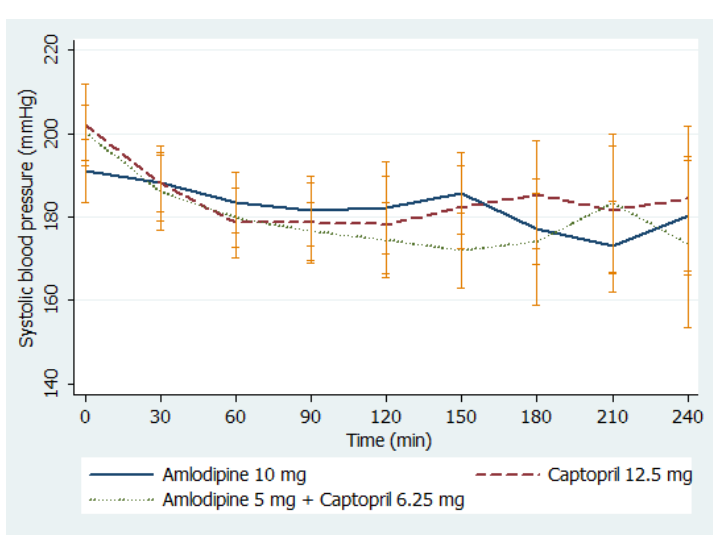

Figure 4: Systolic blood pressure trend during study period.

When compared the efficacy of amlodipine in patients with hypertensive urgency, we found that the blood pressure response was consistent with previous study by Grassi et al. [22]. The response rates in patients who received amlodipine in this study and study by Grassi et al. [22] were similar (41.75\% and $42.8 \%$, respectively). However, the favorable response within $2 \mathrm{~h}$ after drug administration was higher in the study of Grassi et al. [22]. Even the dosage of amlodipine for treatment in our study was higher $(10 \mathrm{mg}$ vs. $5 \mathrm{mg}$ ) than the study of Grassi et al. [22], the discrepancy in response could explain by the difference in the therapeutic threshold. In Grassi et al. [22] study, which blood pressure satisfactory response was defined as SBP and DBP level $<180 \mathrm{mmHg}$ and $<110 \mathrm{mmHg}$ after treatment, respectively or with at least a $20 \mathrm{mmHg}$ reduction in basal SBP and/or a $10 \mathrm{mmHg}$ reduction in basal DBP, while the responder in our study was patients who decrease $15 \%$ to $25 \%$ in MAP and also exclude the patients who lowered blood pressure more than $25 \%$.

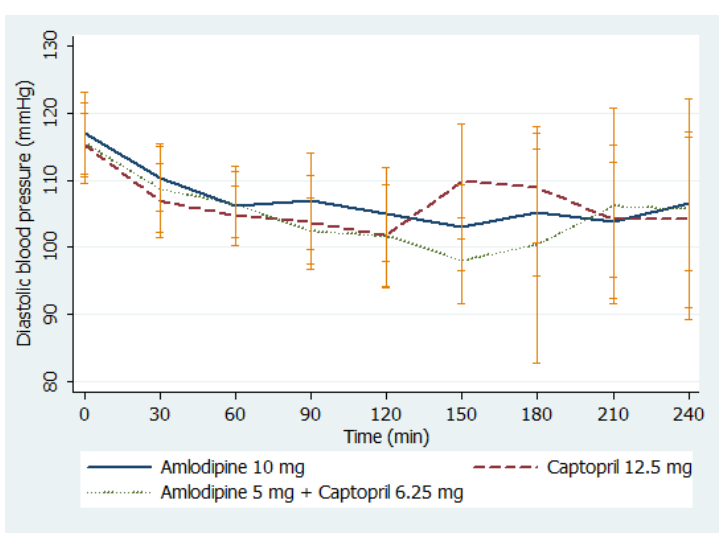

Figure 5: Diastolic blood pressure trend during study period.

Both oral and sublingual captopril is a common used in emergency room. There are many studies demonstrated that sublingual captopril was effective for lowering blood pressure in patients with hypertensive urgency [23] and emergency [24-27]; however, some studies observed that rapid and fast blood pressure reduction by sublingual route was harmful $[28,29]$. In term of efficacy, there were conflict results of the efficacy between oral and sublingual route of captopril. Many studies reported that the sublingual captopril lowered the blood pressure better than the oral captopril [30-32] while there was no difference in lowering blood pressure and plasma renin and angiotensin converting enzyme activity [33]. On the other hand, Karakilic et al. [34] reported that in the first hour after administration, there was no significant difference between sublingual and oral captopril route to decrease blood pressure in patients with hypertensive crisis and suggested that oral captopril use is more appropriate to control blood pressure and 
also prevent undesirable side effects (i.e., hypersensitivity, bitter taste, chemical burn on oral mucosa, etc.) in patients with hypertensive urgency. In this study, $80 \%$ of patients who received oral captopril achieved the blood pressure goal within $2 \mathrm{~h}$ while only $14 \%$ of patients were non-responder. The dosage of oral captopril in this study was 12.5 $\mathrm{mg}$, which was lower compared with most previous studies $(25 \mathrm{mg}$ ) and the response threshold in previous studies was defined as a cut-off instead of percentage reduction in blood pressure [35,36].

From the results, blood pressure lowering patterns including MAP, SBP and DBP were consistent with each drugs' pharmacokinetics. After single dose of amlodipine, blood pressure decreased gradually over $4 \mathrm{~h}$. This finding was consistent with previous studies by Pujadas et al. [37] that the time needed for blood pressure reduction ranged from $30 \mathrm{~min}$ to $100 \mathrm{~min}$ in oral nifedipine which is also a dihydropyrine calcium channel blocker, while the studies of ACEIs, this therapeutic time range was vary from $30 \mathrm{~min}$ to $120 \mathrm{~min}[37,38]$. However, in our study, captopril had onset of action within half an hour and blood pressure slowly raised after $120 \mathrm{~min}$ as the drug may be eliminated. In combination group, blood pressure start to decrease as early as in captopril alone group, however, the effect last longer till $150 \mathrm{~min}$ before blood pressure slowly increased again. Based on the pattern of blood pressure lowering from this study, it suggested that sequential treatment has a promising role as it may not only achieve target within appropriate time but also has long lasting effect for blood pressure control. However, our study was designed to limit for four hours, therefore further study with longer period is needed.

Interestingly, we found that the combination of half-dosed amlodipine and captopril tended to over reach the safety threshold (25.8\%). However, there was no serious adverse event. The results suggested that to reduce MAP more than 25\% from baseline might be safe. Further study with more population is needed to investigate this cut-off for target blood pressure before recommendation.

In this study, responders (MAP reduced $15 \%$ or more within $4 \mathrm{~h}$ ) had a significantly higher MAP at baseline than non-responders while other factor i.e., age, serum creatinine level, duration of hypertension were not significantly difference between groups. This finding was inconsistent with previous studies $[39,40]$, which reported that serum creatinine was the main barrier for achieving target blood pressure in chronic setting. However, we noticed that creatinine level in nonresponders in current study was higher when compared with responders, but there was not significantly difference (Table 3).

\begin{tabular}{|c|c|c|c|c|c|}
\hline Factors & Responders ( $n=57$ ) & Non-responders $(n=25)$ & Mean difference & $95 \% \mathrm{Cl}$ & $P$ value \\
\hline Age (year) & $51.8 \pm 9.9$ & $51.6 \pm 7.8$ & 0.28 & $-4.1,4.7$ & 0.9 \\
\hline Mean arterial pressure $(\mathrm{mmHg})$ & $145.4 \pm 14.1$ & $136.4 \pm 9.9$ & 8.97 & $3.5,14.4$ & $<0.01$ \\
\hline Serum creatinine (mg/dl) & $0.76 \pm 0.21$ & $0.90 \pm 0.32$ & -0.14 & $-0.29,0.01$ & 0.054 \\
\hline Duration of hypertension (month) & $29.0 \pm 37.5$ & $38.2 \pm 48.8$ & -9.17 & $-30,12.2$ & 0.4 \\
\hline
\end{tabular}

Table 3: Factors associated with target blood pressure achievement.

The present study's findings should be interpreted within the context of strengths and potential weaknesses. The major strengths of this study are 1) an RCT which provide better control over possible bias through randomization and blinding, 2) the study's drugs are the common antihypertensive which have been used in daily clinical practice in most Thai hospital settings, and 3) this was the first study in Asia to evaluate the treatment for patients with hypertensive urgency and also the first study to determine the efficacy for half-dose amlodipine and captopril combination. However, this study was designed to measure blood pressure in short time of period (only four hours after administration) and we did not collect the long-term blood pressure control and also other cardiovascular endpoints, further research is needed to determine the best strategies to manage the patients with hypertensive urgency at emergency room and also the maintenance therapy to achieve a better long-term blood pressure control during follow up period to prevent the adverse events, cardiovascular morbidity and mortality, number of hospitalization, and complications.

In conclusion, the efficacy of $10 \mathrm{mg}$ amlodipine, $12.5 \mathrm{mg}$ captopril and combination of $5 \mathrm{mg}$ amlodipine with $6.25 \mathrm{mg}$ captopril for patients with hypertensive urgency to achieve target blood pressure control was similar. Even though, treatment with captopril alone or in combination with amlodipine decreased blood pressure more than those with amlodipine alone, there was no statistical difference. Both major and minor adverse events among the treatments were minimal. This study suggested that three regimens can be can be safely used in emergency room for hypertensive urgency.

\section{Acknowledgments}

This study was supported by the Khon Kaen University Research Fund. The authors thank Professor Pyatat Tasanawiwat and Associate Professor Songsak Kiatchoosakul for improving manuscript and also Mrs. Kaewjai Tepsuthammarut for statistical analysis.

\section{References}

1. Reuler JB, Magarian GJ (1988) Hypertensive emergencies and urgencies: definition, recognition, and management. J Gen Intern Med 3: 64-74.

2. (1993) The Fifth Report of the Joint National Committee on Detection, Evaluation and Treatment of High Blood Pressure. Arch Intern Med 153: 154-183.

3. Chobanian AV, Bakris GL, Black HR, Cushman WC, Green LA (2003) The seventh report of the Joint National Committee on prevention, detection, evaluation and treatment of high blood pressure. Hypertens 42: 1206-1252.

4. Vlcek M, Bur A, Woisetschager C, Herkner H, Laggner AN, et al. (2008) Association between hypertensive urgencies and subsequent cardiovascular events in patients with hypertension. J Hypertens 26: 657-662.

5. Cherney D, Straus S (2002) Management of Patients with Hypertensive Urgencies and Emergencies. J Gen Intern Med 17: 937-945.

6. Muiesan ML, Salvetti M, Amadoro V, di Somma S, Perlini S, et al. (2015 ) An update on hypertensive emergencies and urgencies. J Cardiovasc Med (Hagerstown) 16: 372-382.

7. Mancia G, Fagard R, Narkiewicz K, Redón J, Zanchetti A, et al. (2013) 2013 ESH/ESC Guidelines for the management of arterial hypertension: 
Citation: Kotruchin P, Pachirat O, Pongchaiyakul C (2016) Efficacy and Safety of Amlodipine versus Captopril and their Combination in Hypertensive Urgency: A Randomized Controlled Trial. J Gen Pract (Los Angel) 4: 274. doi:10.4172/2329-9126.1000274

Page 7 of 7

the Task Force for the management of arterial hypertension of the European Society of Hypertension (ESH) and of the European Society of Cardiology (ESC). J Hypertens 31: 1281-1357.

8. Varon J (2008) Treatment of acute severe hypertension: current and newer agents. Drugs 68: 283-297.

9. Kaplan NM (2005) Hypertensive crisis. In: Kaplan's clinical hypertension, (9th edn), Lippincott, Williams, and Wilkins, Philadelphia, USA.

10. Elliott WJ (2001) Hypertensive emergencies. Crit Care Clin 17: 435-451

11. Houston MC (1988) The comparative effects of clonidine hydrochloride and nifedipine in the treatment of hypertensive crises. Am Heart J 115: 152-159.

12. Handler J (2006) Hypertensive urgency. J Clin Hypertens (Greenwich) 8: 61-64.

13. Zeller KR, Von Kuhnert L, Matthews C (1989) Rapid reduction of severe asymptomatic hypertension. A prospective, controlled trial. Arch Intern Med 149: 2186-2189.

14. Bannan LT, Beevers DG, Wright N (1980) ABC of blood pressure reduction. Emergency reduction, hypertension in pregnancy, and hypertension in the elderly. BMJ 281: 1120-1122.

15. Reed WG, Anderson RJ (1986) Effects of rapid blood pressure reduction on cerebral blood flow. Am Heart J 111: 226-228.

16. Bruton LL, Parker L, Blumenthal D, Buxton I (2008) Goodman \& Gilman's: Manual of Pharmacology and Therapeutics, International edition, McGraw-Hill Companies Inc, USA.

17. Joseph JS, Barry LC (2005) Applied Therapeutics: The Clinical Use of Drugs, (8th edn), Washington: Applied Therapeutics Inc, USA.

18. Norris K, Neutel JM (2007) Emerging insights in the first-step use of antihypertensive combination therapy. J Clin Hypertens (Greenwich) 9: 5-14.

19. Prisant LM (2002) Fixed low-dose combination in first-line treatment of hypertension. J Hypertens 20: S11-S19.

20. Skolnik NS, Beck JD, Clark M (2000) Combination antihypertensive drugs: recommendations for use. Am Fam Physician 61: 3049-3056.

21. Kitiyakara C, Guzman N (1998) Malignant hypertension and hypertensive emergencies. J Am Soc Nephrol 9: 133-142.

22. Grassi D, O'Flaherty M, Pellizzari M, Bendersky M, Rodriguez P, et al. (2008) Hypertensive urgencies in the emergency department: evaluating blood pressure response to rest and to antihypertensive drugs with different profiles. J Clin Hypertens (Greenwich) 10: 662-667.

23. Papadopoulos DP, Mourouzis I, Thomopoulos C, Makris T, Papademetriou V (2010) Hypertension crisis. Blood Press 19: 328-336.

24. Ceyhan B, Karaaslan Y, Caymaz O, Oto A, Oram E, et al. (1990) Comparison of sublingual captopril and sublingual nifedipine in hypertensive emergencies. Jpn J Pharmacol 52: 189-193.

25. Hauger-Klevene JH (1985) Captopril in hypertensive crisis. Lancet 28 732-733.
26. Hauger-Klevene JH (1986) Comparison of sublingual captopril and nifedipine. Lancet 25: 219.

27. Sakano T, Okuda N, Sokura N (1981) Captopril in hypertensive emergencies. Hirosh J Mewd Sci 30: 351-354.

28. Marik PE, Rivera R (2011) Hypertensive emergencies: an update. Curr Opin Crit Care 17: 569-580.

29. Gemici K, Karakoç Y, Ersoy A, Baran II, Güllülü S, et al. (1999) A Comparison of Safety and Efficacy of Sublingual Captopril with Sublingual Nifedipine in Hypertensive Crisis. Int J Angiol 8: 147-149.

30. Al-Furaih TA, Mc Elnay JC, Elborn JS, Rusk R, Scott MG, et al. (1991) Sublingual captopril- a pharmacokinetic and pharmacodynamic evaluation. Eur J Clin Pharmacol 40: 393-398.

31. Chetty DJ, Chen LL, Chien YW (2001) Characterization of captopril sublingual permeation: determination of preferred routes and mechanisms. J Pharm Sci 90: 1868-1877.

32. Perez C, Dougnac A, Alvarez M, Andresen M, Diaz O (1991) Sublingual captopril versusnifedipine in the treatment of hypertensive crisis. Rev Med Chil 119: 402-405.

33. Dessì-Fulgheri P, Bandiera F, Rubattu S, Cocco F, Madeddu P, et al. (1987) Comparison of sublingual and oral captopril in hypertension. Clin Exp Hypertens A 9: 593-597.

34. Karakiliç E, Büyükcam F, Kocalar G, Gedik S, Atalar E (2012) Same effect of sublingual and oral captopril in hypertensive crisis. Eur Rev Med Pharmacol Sci 16: 1642-1645.

35. Komsuoglu B, Sengun B, Bayram A, Komsuoglu SS (1991) Treatment of hypertensive urgencies with oral nifedipine, nicardipine, and captopril. Angiology 42: 447-454

36. Cherney D, Straus S (2002) Management of patients with hypertensive urgencies and emergencies; A systematic review of the literature. J Gen Intern Med 17: 937-945.

37. Pujadas R, Jané J, Fornós C, Gago MJ, de la Concepción N (1987) Comparison of sublingual captopril and nifedipine in hypertensive crises. Arch Intern Med 147: 175-176.

38. Damasceno A, Ferreira B, Patel S, Sevene E, Polónia J (1997) Efficacy of captopril and nifedipine in black and white patients with hypertensive crisis. J Hum Hypertens 11: 471-476.

39. Chowdhury EK, Owen A, Krum H, Wing LMH, Ryan P, et al. (2013) Barriers to achieving blood pressure treatment targets in elderly hypertensive individuals. J Hum Hypertens 27: 545-551

40. Kudo N, Yokokawa H, Fukuda H, Sanada H, Miwa Y, et al. (2015) Achievement of Target Blood Pressure Levels among Japanese Workers with Hypertension and Healthy Lifestyle Characteristics Associated with Therapeutic Failure. PLoS One. 10: e0133641. 